\title{
Contra as reformas e o comunismo: a atuação da Ordem dos Advogados do Brasil (OAB) no governo Goulart
} Against reforms and communism:
the performance of the Brazilian Bar Association (OAB)
during Goulart's Government Marco Aurélio Vanucchi Leme de Mattos

\section{Introdução}

Tem-se intensificado nos últimos anos o esforço da historiografia para lançar luz sobre a participação de segmentos da sociedade civil na deposição de João Goulart e no regime implantado a partir de então. ${ }^{1} \mathrm{O}$ presente artigo pre-

\footnotetext{
Marco Aurélio Vannucchi Leme de Mattos é doutor em História Social pela USP e pesquisador colaborador da Unicamp (lememattos@hotmail.com).

Este artigo reproduz e aprimora reflexões presentes na tese de doutorado do autor, Os cruzados da ordem jurídica. A atuação da Ordem dos Advogados do Brasil (OAB), 1945-1964 (2011).

Artigo recebido em 30 de dezembro de 2011 e aprovado para publicação em 4 de abril de 2012.
} 
tende contribuir para tal esforço, examinando a adesão da Ordem dos Advogados do Brasil (OAB) à coalizão de forças que executou o golpe de 1964.

A natureza acentuadamente heterogênea, do ponto de vista social e de projetos, do bloco golpista recomenda a realização de investigações monográficas que examinem, para além das motivações comungadas pelos diferentes agentes, as razões específicas de cada um dos setores participantes do movimento que culminou na derrubada de Goulart. Determinados segmentos da sociedade civil, como o empresariado, os partidos políticos, o movimento feminino, a imprensa e a Igreja Católica foram objeto de estudos de fôlego. As entidades dirigidas pela elite jurídica receberam menos atenção dos pesquisadores, apesar da existência de estudos importantes. ${ }^{2}$ No entanto, os juristas desempenharam um papel relevante tanto na legitimação da mobilização anti-Goulart quanto na construção institucional da ditadura militar.

A OAB, especificamente, já usufruía, no início da década de 1960, de uma significativa projeção pública, fundada especialmente no seu papel de representante de uma categoria profissional que gozava de prestígio social e ostentava tradição na direção do Estado. Os estudos disponíveis sobre a $\mathrm{OAB}$ não são numerosos e concentram-se no pós-1964. Assim, o presente artigo propõe-se, também, a oferecer elementos para a compreensão da trajetória da entidade antes que ela se tornasse, a partir de meados da década de 1970, um dos pilares da oposição à ditadura militar e uma das protagonistas do processo de redemocratização.

\section{A renúncia de Jânio Quadros}

Em meio à crise político-militar deflagrada pela renúncia de Jânio Quadros, o presidente da OAB, Prado Kelly, apresentou ao Conselho Federal da entidade uma moção sobre o tema, aprovada por aclamação na reunião de 29 de agosto de 1961 (Arquivo do Conselho Federal da OAB - CF-OAB -, Ata de sessão do CF, 29/8/1961). Malgrado seu caráter genérico, o documento pregava o respeito à Constituição - o que, naquele contexto, significava a defesa da posse do vice-presidente da República, João Goulart. Ao condenar o "extremismo da direita", o Conselho Federal recusava a posição golpista dos setores civis e das Forças Armadas liderados pelos ministros militares e por Carlos Lacerda, mas, por outro lado, ao censurar igualmente o "extremismo da esquerda", aludia à disposição de setores de esquerda de recorrer às armas, se fosse necessário, para fazer valer o caminho legal. Ao pregar uma saída equilibrada para a crise e não propugnar explicitamente a posse de Goulart com plenos poderes presidenciais, o Conselho Federal inclinava-se para uma solução de compromisso, que bem poderia 
ser o parlamentarismo - já aventado naquele momento (Skidmore, 1982: 252-259; Benevides, 1981:118). Um ano mais tarde, ao despedir-se do posto de bâtonnier, Prado Kelly fez o elogio da solução parlamentarista, por ter evitado, segundo seu entendimento, a eclosão de uma guerra civil no país (CF-OAB, Ata de sessão do CF, 11/8/1962).

\section{A tomada de posição contra Goulart}

Em meados de 1962, quando a defesa da posse de Goulart pelo Conselho Federal da $\mathrm{OAB}$ estava prestes a completar um ano, o órgão assumiu um oposicionismo ao presidente do qual não daria evidências de qualquer recuo. A partir de então, e até o golpe de 1964, o Conselho Federal passou a atuar diretamente sobre o cenário político, manifestando-se com frequência sobre iniciativas governamentais e sobre a situação nacional. Tal atitude francamente politizada apenas guardava paralelo, na trajetória da $\mathrm{OAB}$, com a ação antiestadonovista do órgão no biênio 1944-1945 (Mattos, 2011:45-75).

O primeiro sinal do engajamento do Conselho Federal na oposição a Goulart foi a intervenção feita por Wilson Regalado Costa na sessão de 24 de julho de 1962. Na ocasião, o conselheiro federal pronunciou-se a respeito da infiltração comunista da qual o Brasil seria vítima e solicitou que o órgão constituísse uma comissão para apurar o fato. O conselheiro federal Aragão Bozano discordou da proposta, argumentando que tal medida não estava entre as atribuições do órgão. No entanto, o conselheiro Gaston Luís do Rego, em socorro à proposição de Wilson Costa, procurou adequá-la ao estatuto da OAB. O risco à ordem jurídica representado pela infiltração comunista justificava, no entender de Gaston Rego, uma tomada de posição do Conselho Federal. O conselheiro mostrou-se especialmente preocupado com as mobilizações grevistas e denunciou a coação exercida pelos líderes paredistas, "conhecidíssimos agitadores”, contra o Congresso Nacional. Os parlamentares, temerosos de atos que trouxessem a desordem ao país, encontravam-se, segundo o conselheiro federal, como que chantageados pelos grevistas. Exortou assim o Conselho Federal a agir em nome de sua própria sobrevivência, pois "no regime soviético, para onde querem nos conduzir", a OAB seria extinta, "de vez que o patrocínio das causas incumbe aos agentes do Estado." Ao concluir sua intervenção, o conselheiro propôs que o organismo manifestasse às autoridades públicas sua preocupação frente à infiltração comunista e às "facilidades com que se movimentam em sua ação subversiva os agentes do marxismo colocados até em posição de comando e em pontos-chave na administração pública" (CF-OAB, Ata de sessão do $\mathrm{CF}$, 24/7/1962). 
Na sessão seguinte do Conselho Federal, Wilson Costa apresentou uma nova indicação sobre o tema da infiltração comunista no país (CF-OAB, Ata de sessão do CF, 31/7/1962). Ao se pronunciar, na condição de relator da matéria, sobre a indicação, o conselheiro Temístocles Cavalcanti endossou a posição de Wilson da Costa quando afirmou enxergar a "deterioração do processo democrático e constitucional" e uma conjuntura de preparação para a subversão da ordem vigente (CF- OAB, Ata de sessão do CF, 7/8/1962).

Em sessão extraordinária, convocada para debater o tema, Temístocles Cavalcanti apresentou uma moção que foi aprovada unanimemente pelo Conselho Federal. Uma longa justificativa para a tomada de posição do Conselho Federal iniciava o documento, que, em síntese, afirmava que o órgão agia em defesa da ordem jurídica e do exercício da advocacia, colocados em risco pelo "clima de agitação e pronunciamentos existentes no país”. A moção também denunciava a deterioração do regime democrático, rejeitava soluções extremistas à esquerda e à direita (o que pode ser interpretado como a quebra da ordem constitucional) e expressava sua crença na democracia representativa. $\mathrm{O}$ manifesto do Conselho Federal foi divulgado para todos os membros do Congresso Nacional e todas as seções estaduais da $\mathrm{OAB}$, assim como para jornais, rádios e televisões (CF-OAB, Ata de sessão do CF, 9/8/1962). Com efeito, no dia seguinte à aprovação do documento, o Diário de Notícias e o Correio da Manhã publicaram-no na íntegra (Diário de Notícias, 10/8/1962, $1^{\text {a }}$ seção, p. 1 e 3; Correio da Manhã , 10/8/1962, $1^{\circ}$ caderno, p. 12).

No dia 11 de agosto de 1962, realizou-se a cerimônia de posse de Povina Cavalcanti na presidência da $\mathrm{OAB}$. Ao contrário do que ocorrera nos anos anteriores, os discursos da cerimônia foram dominados pela conjuntura política e não pelas questões corporativas, as quais não foram mencionadas, exceto no trecho final do discurso de Povina Cavalcanti, que tratava da proletarização da categoria dos advogados, embora a relacionasse com um tema de conjuntura: a inflação (CF-OAB, Ata de sessão do CF, 11/8/1962).

No seu discurso de despedida, Prado Kelly fez uma profissão de fé liberal. Seu pronunciamento reproduziu temas caros ao liberalismo, como o caráter inato da liberdade para o homem, a legitimidade da existência de diversas correntes de opinião na sociedade e a alternância pacífica no poder entre tais correntes. Não há dúvida de que a pregação do bâtonnier, em sua despedida do posto, tinha alvo certo: o comunismo, cujo espectro ele reconhecia assombrando o Brasil (CF-OAB, Ata de sessão do CF, 11/8/1962).

Já o discurso de Povina Cavalcanti tomou contornos evidentemente alarmistas quanto ao cenário político. O novo presidente da $\mathrm{OAB}$ afirmou temer o risco de um "colapso institucional" e via os horizontes "carregados de maus presságios” (CF-OAB, Ata de sessão do CF, 11/8/1962). Ainda que não mencio- 
nasse diretamente o nome do presidente da República, fica claro no discurso de Cavalcanti que era ele - e também as classes populares - quem ameaçava a estabilidade do regime. O novo presidente da $\mathrm{OAB}$ revelou, na cerimônia de sua investidura, uma atitude sensivelmente mais radical que a de seu predecessor. Ainda que crítico de Goulart, Prado Kelly não o acusava de representar um risco para a institucionalidade liberal. De sua parte, Povina Cavalcanti denunciou o governo como a principal ameaça à ordem vigente.

No dia 18 de setembro de 1962, o bâtonnier afirmou que o país experimentava o agravamento da crise política. O Conselho Federal aprovou, então, o pedido de seu presidente para que pudesse convocar uma sessão extraordinária caso os acontecimentos políticos degenerassem em risco para a ordem jurídica (CF-OAB, Ata de sessão do CF, 18/9/1962). A tese de que o país se encontrava à beira de uma ruptura da legalidade, cara a Povina Cavalcanti, já havia sido enunciada por Temístocles Cavalcanti e referendada pelo Conselho Federal na moção de agosto de 1962. Adotando essa postura alarmista, muito antes dos episódios que causaram o agravamento das tensões sociais no país (como a Revolta dos Sargentos, a campanha das Reformas de Base e o comício da Central do Brasil), o órgão contribuiu para a disseminação do clima de temor que antecedeu e legitimou a deposição de Goulart.

\section{Contra as Reformas de Base e a mobilização popular}

Em abril de 1963, ao fazer a saudação aos conselheiros federais na abertura dos trabalhos do Conselho Federal, Oto Gil deixou claro que o órgão continuava em vigília em relação à conjuntura nacional. Responsabilizou o "caudilhismo indígena" e os "demagogos" pelas ameaças que pairavam sobre a ordem jurídica do país. E adiantou a oposição do órgão às Reformas de Base:

Haverá, porém, onde redobrar a nossa vigilância e pugnacidade: é quanto aos propósitos, ainda encabuçados, da Reforma Constitucional, que se pretende obter do Congresso Nacional sob a mais odienta coação (...) (CF-OAB, Ata de sessão do CF, 2/4/1963).

Naquele mês, o deputado Bocaiúva Cunha, líder do PTB na Câmara dos Deputados, apresentou um projeto que pretendia viabilizar a reforma agrária, alterando a Constituição ao permitir o pagamento de indenização pelas desapropriações de terra com títulos da dívida pública (Toledo, 2004: 55-56; Benevides, 1981: 189-194; Hippolito, 1985: 224-232). Logo, o conselheiro Renato 
Ribeiro pediu que o Conselho Federal examinasse o projeto de lei. Nomeado relator da indicação de Renato Ribeiro, Carlos Medeiros Silva apresentou seu parecer no dia 30 de abril. Nele, defendia o projeto de Bocaiúva Cunha, mas fazia uma importante ressalva, ao observar que a proposta não protegia suficientemente as indenizações da inflação (CF-OAB, Ata de sessão do CF, 30/4/1963). Entretanto, no dia 14 de maio, o conselheiro federal Carlos Bernardino de Aragão Bozano, apoiado por 15 delegações, apresentou ao Conselho Federal um parecer substitutivo ao de Carlos Medeiros. O novo parecer refutava firmemente o projeto Bocaiúva (CF-OAB, Ata de sessão do CF, 14/5/1963). O teor do substitutivo era o seguinte:

A Ordem dos Advogados do Brasil manifesta sua contrariedade à pretendida reforma constitucional, eis que, além de perigosa como precedente, atenta contra o direito de propriedade e resulta totalmente desnecessária ao fim declarado, o de proporcionar aos trabalhadores rurais o acesso às terras. Dentro na Constituição da República, como na legislação ordinária em vigor, há elementos suficientes para a mudança da estrutura agrária do país, atendendo ao Homem e às necessidades da produção, sem que sejam golpeados os direitos fundamentais dos cidadãos e com grave risco para a ordem jurídica (CF-OAB, Ata de sessão do CF, 14/5/1963).

O novo parecer foi aprovado por ampla maioria (CF-OAB, Ata de sessão do CF, 14/5/1963). O resultado demonstrou que já se consolidara no Conselho Federal da $\mathrm{OAB}$ a posição de recusa ao projeto Bocaiúva, que também se tornaria francamente majoritária tanto no PSD quanto na UDN.

Em 20 de março de 1964, em meio à radicalização política que marcou o fim do governo Goulart, o Conselho Federal realizou uma sessão extraordinária para debater os últimos acontecimentos. $\mathrm{O}$ órgão, nessa ocasião, aprovou uma moção centrada na defesa da legalidade, pregando a restauração da "tranquilidade pública, perturbada por movimentos de agitação, ameaças e atos contrários à Constituição e às leis". O Conselho Federal asseverava reconhecer a legitimidade das reivindicações do campo reformista, mas lhe reprovava o uso de "meios de propaganda de soluções extraconstitucionais." O documento foi encaminhado à Presidência da República, ao Congresso Nacional, às Assembleias Legislativas dos estados, ao Supremo Tribunal Federal (STF), ao Tribunal Federal de Recursos e às seções estaduais da $\mathrm{OAB}$ (CF-OAB, Ata de sessão do CF, 20/3/1964). Nos dias seguintes, jornais divulgaram o manifesto da $\mathrm{OAB}$ (Correio da Manhã, 22/3/1964, $1^{\circ}$ caderno, p. 24). 
Houve, contudo, vozes discordantes na aprovação da moção. O conselheiro Paulo Belo propôs adicionar um trecho ao documento aprovado que continha tanto um apoio às Reformas de Base quanto um apelo para que a luta política não violasse a legalidade. Todavia, a emenda de Paulo Belo foi rejeitada pela maioria do Conselho Federal (CF-OAB, Ata de sessão do CF, 20/3/1964). O Diário de Notícias reproduziu trechos do acalorado debate que cercou a aprovação da moção de 20 de março. Segundo o periódico, o conselheiro federal Wilson do Egito Coelho destacou-se na refutação aos ataques feitos por outros membros do Conselho Federal ao presidente da República, considerando-os inconsistentes. Por sua vez, conselheiros federais alinhados à posição hegemônica no organismo desfiaram acusações ao governo federal. Gaston Luís do Rego procurou deslegitimar o apoio popular às iniciativas de Goulart: "O presidente da República (...) tem dito que governa com o povo, mas esse povo de que ele fala são entidades espúrias.” Renato Ribeiro sugeriu "haver o deliberado propósito de destruir a estrutura jurídica do país, e isso exatamente por homens incapazes de construir". E afirmou ainda que as Reformas de Base eram recusadas por todos os brasileiros. Ademais, alguns conselheiros denunciaram a inconstitucionalidade de algumas medidas governamentais, como a desapropriação de terras, a encampação de refinarias e o tabelamento de aluguéis (Diário de Notícias, 21/3/1964, $1^{\text {a }}$ seção, p. 2).

O Conselho Federal da OAB, com exceção de poucas vozes, identificava a questão social com o risco à ordem jurídica. Alguns setores da oposição a Goulart, destacadamente a "Bossa Nova" da UDN e a "Ala Moça" do PSD inclinaram-se, por algum momento, pelas reformas propostas pelo governo, considerando-as um antídoto contra o proselitismo comunista (Benevides, 1981: 123-124). Entretanto, esta nunca foi a posição majoritária no Conselho Federal. O órgão sempre refutou as reivindicações populares, lançando mão da "camisa de força" representada pela Constituição de 1946. Ironicamente, a defesa da legalidade serviu como obstáculo para impedir que a experiência democrática iniciada em meados da década de 1940 se aprofundasse, com a expansão dos direitos políticos e sociais.

\section{A campanha de desestabilização de Goulart}

Como nota Carlos Fico, na análise do processo político que culminou no golpe de 1964, é necessário distinguir a campanha de desestabilização do governo, desenvolvida a partir da sociedade civil, da ação militar stricto sensu, responsável pela deposição de Goulart (Fico, 2004: 55). A campanha arregimentou o apoio de amplos grupos sociais, disseminando o temor do comunismo. Seu efeito político revestiu-se de duplo caráter: defensivo, ao se constituir em contrapeso às propos- 
tas reformistas do governo e à mobilização das organizações de esquerda e dos sindicatos de trabalhadores; ofensivo, ao oferecer legitimidade à intervenção golpista (Dreifuss, 1981: 230, 281; Reis Filho, 2001: 335-336; Motta, 2002: 237-249).

Não há evidências de que a $\mathrm{OAB}$ tenha participado da conspiração contra Goulart, ainda que seja lícito supor que alguns de seus conselheiros federais, na condição de dirigentes do complexo IPES/IBAD ou de políticos da UDN, o tenham feito. Todavia, não há qualquer dúvida de que a entidade se engajou na campanha de desestabilização de Goulart, como provam os pronunciamentos e atitudes do Conselho Federal entre 1962 e 1964. Nesse período, tópicos centrais da campanha anticomunista, como a oposição entre comunismo e democracia, a exortação à defesa da "civilização ocidental", o progressivo controle do aparato estatal e de organismos civis pelos comunistas e o risco à estabilidade social e jurídica representado por Goulart e seus aliados fizeram-se presentes nos documentos do Conselho Federal e nos pronunciamento de seus integrantes.

A OAB justificava sua intervenção na vida política do país recorrendo a seu papel (autoatribuído) de guardiã da institucionalidade democrático-liberal, desempenhado supostamente de modo neutro em relação às lutas sociais, e à sua prerrogativa de representar o conjunto dos advogados. Essas fontes de legitimidade da atuação política da $\mathrm{OAB}$ devem ser consideradas na avaliação de sua contribuição à campanha desestabilizadora acionada contra Goulart. O impacto do oposicionismo da entidade possivelmente foi de particular relevância entre os advogados, grupo tradicional no interior das classes médias, que se constituiu, como se sabe, no suporte social fundamental para a mobilização civil contra o governo. A tomada de posição da $\mathrm{OAB}$ deu-se em nome da preservação da ordem jurídica, um argumento a que os advogados se mostravam particularmente sensíveis. Ademais, o combate da entidade a um programa que visava à redistribuição de renda e poder alinhava-se ao comportamento político ainda predominante entre os advogados, marcado pela resistência ao aprofundamento da incorporação política e econômica das classes populares, malgrado o processo de diferenciação político-ideológica que atingia a categoria profissional, e as classes médias, de modo geral, desde a Primeira República (Fausto, 1997: 93-110; Saes, 1996: 454-505; Mattos, 2011: 214-222).

As manifestações do Conselho Federal da OAB tendiam a atingir um público amplo, repercutidas e noticiadas pela grande imprensa e, igualmente, pelas seções estaduais da $\mathrm{OAB}$ (é preciso notar a capilaridade da entidade, instalada em todas as unidades da Federação e em grande parte das cidades brasileiras) e por outras organizações de advogados.

É importante registrar que a campanha de desestabilização de Goulart contou com a adesão de outras entidades de advogados, o que revela a ampla participação da elite profissional, que em geral controlava tais entidades, na mobili- 
zação oposicionista. Entre 24 de março e $1^{\circ}$ de abril de 1964, o Instituto dos Advogados Brasileiros (IAB), o Instituto dos Advogados de São Paulo, a Associação dos Advogados Democratas e a Associação dos Advogados de São Paulo (AASP) divulgaram documentos contrários às Reformas de Base ou favoráveis à deposição de Goulart (Fagundes, 1995: 229-230; Mattos, 2011: 30; Saes, 1996: 502; Schubsky, 2006: 58-59).

\section{Os vínculos de classe dos conselheiros federais}

Os vínculos de classe dos conselheiros federais estavam na base do antagonismo do Conselho Federal da $\mathrm{OAB}$ em relação a Goulart, conquanto não constituíssem os móveis exclusivos da adesão do organismo à campanha antigovernista. $\mathrm{O}$ levantamento de dados biográficos a respeito dos conselheiros federais demonstra, ao menos para uma parte deles, uma ligação estreita com as classes dominantes (amplamente contrariadas com o reformismo do governo federal), das quais eram integrantes ou consultores jurídicos (Mattos, 2011: 183-185). Assim, Nehemias Gueiros, presidente da OAB entre 1956 e 1958, era "patrono de conhecidos grupos econômicos que se opunham a Goulart” (Coelho, 1996: 44). Miguel Seabra Fagundes, bâtonnier entre 1954 e 1956, integrou o conselho técnico da Confederação Nacional do Comércio. Temístocles Marcondes Ferreira, vice-presidente da OAB entre 1963 e 1965, era fazendeiro, banqueiro e industrial. Fundou e dirigiu a Companhia Editora Nacional e o Grupo Atlântica de Seguros Sociais. Alberto Barreto de Melo, secretário-geral da Ordem entre 1952 e 1965, foi assessor técnico da Associação dos Plantadores de Cana de Sergipe. José Augusto Bezerra de Medeiros presidiu, de 1959 a 1961, a Associação Comercial do Rio de Janeiro. Todos os exemplos dados referem-se a bacharéis dotados de significativa capacidade de influenciar as decisões do Conselho Federal em razão de sua condição de dirigentes da $\mathrm{OAB}$ ou de suas credenciais como homens públicos (Calicchio, 2002; Malin, 2002; Oliveira, 1968: 361-363).

\section{Os vínculos político-partidários dos conselheiros federais}

O perfil partidário do Conselho Federal contribuiu para sua tomada de posição contra o governo Goulart. Desde sua organização, em 1933, o Conselho Federal contava com uma elevada presença de políticos profissionais, muitos dos quais exerciam mandatos no Congresso Nacional. No pós-1945, a grande maioria dos conselheiros federais com filiação partidária pertencia ao PSD e à UDN (Mattos, 2011: 177-183). Assim, num período de forte polarização políti- 
co-ideológica, era natural que os posicionamentos partidários dos conselheiros federais contaminassem sua atuação no órgão corporativo. Sabe-se que a aliança PSD-PTB se deteriorou ao longo do governo Goulart, e que a maioria dos pessedistas recusou-se a empenhar seu apoio às proposições reformistas do governo federal, tendo mesmo uma boa parte deles chegado a fazer-lhe oposição aberta. Era o caso do deputado federal pessedista Nelson Carneiro, conselheiro federal da OAB entre 1962 e 1963 e membro da Ação Democrática Parlamentar (ADP), o bloco interpartidário que deu suporte parlamentar à campanha de desestabilização contra Goulart (Dreifuss, 1981: 321).

Ainda mais significativa para a compreensão do oposicionismo do Conselho Federal é a forte influência que a UDN, especialmente sua "Ala dos bacharéis", exercia no meio jurídico, incluindo as seções estaduais e o Conselho Federal da OAB desde sua fundação, em 1945. Vários bacharéis udenistas compuseram a instância diretiva máxima da Ordem, e alguns deles exerceram mesmo a função de bâtonnier, como Raul Fernandes e Prado Kelly (Mattos, 2011: 45-75, 155-161, 177-183).

Ainda em termos de vínculos políticos, é necessário registrar um aspecto do Conselho Federal praticamente ignorado: a proximidade de seus integrantes e, particularmente, de sua diretoria com o complexo IPES/IBAD, um dos mais importantes núcleos da conspiração contra Goulart. Assim, Povina Cavalcanti, o presidente da OAB entre 1962 e 1965, além de filiado ao complexo IPES/IBAD, era diretor da Associação dos Amigos das Nações Cativas, entidade dedicada à campanha anticomunista nos moldes da ação desenvolvida pelo IPES. Como Povina Cavalcanti, Alberto Barreto de Melo era dirigente da Associação dos Amigos das Nações Cativas, além de associado do complexo IPES/IBAD. Temístocles Marcondes Ferreira era dirigente do IPES. João Nicolau Máder Gonçalvez, que integrou o Conselho Federal da OAB por todo o período democrático, com exceção do ano de 1957, é descrito por René Dreifuss como um dos líderes do IPES. Miguel Seabra Fagundes colaborou com o IPES. Finalmente, Temístocles Cavalcanti, membro do Conselho Federal da OAB entre 1961 e 1962, coordenou um curso de formação política destinado a empresários e administradores organizado pelo IPES, do qual era associado (Dreifuss, 1981: 174-176, 293, 438, 451).

\section{A cultura politica do Conselho Federal}

$\mathrm{A}$ ameaça à posição socioeconômica defendida pela $\mathrm{OAB}$, consubstanciada nas proposições reformistas de Goulart e na mobilização popular, foi respondida numa chave conservadora, condizente com a cultura política dominante na en- 
tidade. Denise Rollemberg (2008: 89) sublinha a "identidade da OAB com a cultura política de direita que estruturou as forças civis" na derrubada de Goulart. A matriz da cultura política da $\mathrm{OAB}$ era o pensamento liberal de corte moderado ou mesmo conservador, hegemônico entre os bacharéis de direito desde, ao menos, 0 período de formação do Estado nacional (Adorno, 1988: 47-53, 239-246; Vianna, 1986: 91-115; Mattos, 2011: 39-72, 214-220). A partir de 1945, esse ideário foi expresso de modo proeminente, ainda que não exclusivo, pela UDN. ${ }^{3}$

No início da década de 1960, destacaram-se três elementos constitutivos da cultura política prevalecente no Conselho Federal da OAB, organizadores de seu oposicionismo: o elitismo, o formalismo e o anticomunismo.

O exercício da direção política do país deveria restringir-se a um grupo credenciado por suas origens sociais, tradições familiares, formação intelectual e experiência político-profissional, do qual os conselheiros federais certamente se sentiam parte. $\mathrm{O}$ reverso dessa crença era a profunda desconfiança em relação à participação das classes populares, vistas como manipuláveis e desordeiras. $\mathrm{O}$ discurso de posse de Povina Cavalcanti revela esse elitismo, tanto sob a forma do que Maria Victoria Benevides (1981: 252-258) denomina "presciência das elites", quanto pela desconfiança em relação à ação política popular, acusada de irracional:

Quando a autoridade pública exprimir sentimentos e pregões democráticos distorsivos, atribuindo-os a coletividades desgarradas do espírito unitário da Pátria, a ação dos advogados é efetivamente criadora da liberdade. (...) Não nos arreceiemos de contrariar a própria opinião pública, se verificarmos que ela está envenenada pela paixão e pela ira. Há contrafações democráticas em muitas atitudes populares teleguiadas (CF-OAB, Ata de sessão do CF, 11/8/1962).

Noutra passagem, usando termos como "multidão histérica" e "turbas iradas", ele lembrou o povo que se negou a absolver Cristo: "A turba pode venerar César, mas César passa; é o tufão, é ruína, é espoliação, é miséria. Transitório o seu reinado, não tem aurora, mas é certo, infalível, fatal o seu ocaso" (CF-OAB, Ata de sessão do CF, 11/8/1962). A nenhum conselheiro federal podia escapar que o novo bâtonnier mencionava a figura do imperador romano para se referir a Goulart.

Durante o governo Goulart, o Conselho Federal negou-se a apoiar qualquer mudança que incorporasse interesses sociais excluídos, insistindo na defesa formalista da ordem jurídica. O órgão identificava os pleitos econômicos e políticos dos grupos subalternos com o risco da subversão da ordem jurídica. Desse modo, jamais se dispôs a debater o conteúdo das reivindicações dos movimentos 
populares. A elas contrapunha os dispositivos da Constituição de 1946, que considerava imutável. $\mathrm{O}$ formalismo do Conselho Federal alicerçou seu combate às Reformas de Base e, especialmente, à reforma agrária. Observe-se, como faz Daniel Aarão Reis (2001: 332-341), que a posição legalista no combate a Goulart não foi sustentada apenas pela $\mathrm{OAB}$, mas pelo conjunto das forças que se levantaram contra o governo. Contudo, o limite ao formalismo do Conselho Federal era seu compromisso com a conservação da ordem social, evidenciado no aplauso à deposição de Goulart, um indubitável ato de ruptura constitucional.

$\mathrm{O}$ anticomunismo professado pela $\mathrm{OAB}^{4}$ significou uma reação às perspectivas de ampliação dos direitos políticos e sociais das classes populares e de sua contrapartida necessária: a diminuição dos privilégios usufruídos pelos grupos dominantes. A escalada do protagonismo político popular e o programa reformista do governo federal eram considerados prenúncios da comunização do país. Deve-se lembrar que o anticomunismo exerceu uma força mobilizadora fundamental no pré-golpe. Como anota Rodrigo Motta (2002: 271-276), o anticomunismo foi o argumento capaz de agregar a heterogênea frente que derrotou Goulart.

\section{Questões corporativo-institucionais}

De todo modo, a adequada compreensão das razões do antagonismo da $\mathrm{OAB}$ em relação ao governo Goulart exige que se considerem, também, os interesses específicos da entidade, relacionados à sua consolidação institucional e às demandas corporativas dos advogados. A partir da década de 1950, o Conselho Federal começou a se dedicar a uma nova agenda corporativa. ${ }^{5}$ A novidade era a incorporação de temas relacionados aos interesses econômicos e às condições de trabalho dos advogados. Até então, a ação do Conselho Federal no âmbito corporativo se havia limitado quase somente à seleção e fiscalização dos advogados. $\mathrm{O}$ pano de fundo do investimento do organismo numa pauta corporativa renovada foram as transformações e dificuldades experimentadas pela categoria profissional, em grande medida decorrentes da modernização do capitalismo brasileiro. ${ }^{6}$ Nesse período, o paradigma liberal que moldava tradicionalmente a profissão passou a conviver crescentemente com a figura do advogado-empregado (do Estado ou de empresas privadas). O Conselho Federal enfrentou as transformações sofridas pela categoria profissional com pragmatismo. Assim, reconheceu a advocacia preventiva, conformou-se com o assalariamento dos advogados e procurou garantir proteção social a eles.

Porém, o órgão temeu pela proletarização da profissão, efeito indesejado do assalariamento dos advogados e da inflação de diplomas de direito. Nas déca- 
das de 1950 e 1960, o tema da proletarização dos advogados tornou-se constante nas sessões do Conselho Federal da OAB. Ao tratar, em 1959, do projeto de previdência dos advogados em tramitação na Câmara dos Deputados, o conselheiro federal da OAB Carlos Bernardino de Aragão Bozano lamentou que os advogados se proletarizassem sem gozar, em contrapartida, a proteção social assegurada aos trabalhadores urbanos. Em 1962, ocupando-se também da previdência social dos advogados, o conselheiro federal Letácio Jansen alarmava-se com a situação de que um advogado-empregado pudesse receber um salário menor que um motorista da Câmara dos Deputados (Gueiros, 1964: 184, 208).

O organismo apostou na redução do número de advogados, no alargamento do campo da advocacia e na implantação de dispositivos de proteção social para frear o processo de proletarização. As duas últimas iniciativas foram razoavelmente bem sucedidas, como demonstram a aprovação do novo estatuto da $\mathrm{OAB}$ e da lei previdenciária dos advogados. Contudo, o Conselho Federal descobriu-se impotente para fazer face ao crescimento exponencial de advogados e, especialmente, de bacharéis em direito (Dantas, 2006: 78-85; Marros, 2011: 78-110).

Como se pode notar, a agenda corporativa revelou-se urgente para a (tentativa de) preservação do status social dos advogados, mas também da legitimidade da $\mathrm{OAB}$ frente à categoria profissional. Em outros termos, a dedicação à defesa da corporação decorreu, igualmente, da necessidade da OAB firmar seu papel como representante dos interesses da categoria profissional perante o surgimento de concorrentes para o cumprimento de tal tarefa, notadamente os sindicatos de advogados.

As notícias de fundação de entidades concorrentes com a $\mathrm{OAB}$ no âmbito sindical surgiram no início da década de 1950. A direção da entidade temeu o surgimento de sindicatos, que poderiam vincular-se ao Estado e ser dirigidos por advogados esquerdistas. Receou também a redução de seu papel como representante dos interesses da categoria profissional - o que poderia fazer decrescer, por conseguinte, sua força entre os advogados e seu prestígio junto ao Estado. O Conselho Federal procurou desestimular a criação de sindicatos de advogados ao incorporar, entre as atribuições legais da $\mathrm{OAB}$, a ação sindical e dispensar o advogado do pagamento do imposto sindical (Mattos, 2011: 224-230).

O cumprimento da agenda corporativa impunha ao Conselho Federal o reforço dos laços de colaboração com o Estado, especialmente com o governo federal e o Congresso Nacional. Historicamente, o Conselho Federal usufruía de uma interlocução privilegiada com o Estado (Mattos, 2011: 196-210). Os dirigentes da $\mathrm{OAB}$ contavam com acesso direto às principais autoridades da República, nos três poderes. Em geral, o Estado mostrava-se receptivo às demandas da OAB. No início da década de 1960, entretanto, o Conselho Federal expe- 
rimentou uma crise aberta na sua relação com o governo Goulart, derivada não apenas da franca oposição do órgão à política de reformas do presidente da República, mas também da percepção de que o governo desrespeitava o padrão de acesso da $\mathrm{OAB}$ ao Executivo federal. Habituados a ser prontamente atendidos nos gabinetes ministeriais ou a receber, na sede da $\mathrm{OAB}$, importantes autoridades governamentais, os dirigentes da entidade ressentiram-se do distanciamento do governo Goulart. E exasperaram-se com a interlocução que o governo estabeleceu com setores subalternos da categoria profissional, como os sindicatos de advogados.

O processo de regulamentação da lei previdenciária dos advogados, aprovada em meados de 1962, revelou as insatisfações do Conselho Federal com Goulart no que tangia à questão corporativa-institucional. Em janeiro de 1963, Povina Cavalcanti atacou, em entrevista ao jornal $O$ Globo, a condução, pelo governo, da questão previdenciária. $\mathrm{O}$ presidente da $\mathrm{OAB}$ expôs, assim, a sensação de duplo desprestígio experimentada pela elite dos advogados: o que atingia a categoria profissional, ameaçada de desclassificação social, e o que se abatia sobre a $\mathrm{OAB}$, diminuída no seu papel de interlocutora privilegiada do Estado. Evidentemente a ameaça de proletarização que pesava sobre os advogados não era imputada ao governo, conquanto Povina Cavalcanti o acusasse de omissão frente à questão. Contudo, Cavalcanti queixava-se amargamente do afastamento do governo em relação à $\mathrm{OAB}$, evidenciando a redução da capacidade de persuasão da entidade junto ao governo.

A insatisfação do Conselho Federal aumentou quando o Ministério do Trabalho dissolveu a primeira comissão encarregada de regulamentar a lei de previdência da categoria profissional para incluir, ainda que mantivesse um representante da OAB, um representante do Sindicato dos Advogados (Gueiros, 1964: 209-214). A medida ameaçava tanto o modelo previdenciário propugnado pela entidade quanto sua pretensão de exercer com exclusividade a representação dos interesses dos advogados. Em carta de outubro de 1963, endereçada ao presidente da seção fluminense da $\mathrm{OAB}$, Povina Cavalcanti tratou do assunto:

Não sei até onde vão os poderes dessa Comissão [a nova comissão de regulamentação da lei], mas a verdade é que não nos foi dada a mínima satisfação, nem concordaríamos, depois dos fatos narrados, com a participação em novo Grupo de Trabalho com representante do Sindicato dos Advogados. Ou representamos nós a classe, como seu órgão supremo, ou a Comissão que resolva os seus problemas políticos sem a nossa interferência (Gueiros, 1964: 214). 


\section{Ditadura militar}

Na primeira sessão do Conselho Federal da OAB após o golpe civil-militar que depôs Goulart, o presidente da Ordem, Povina Cavalcanti, saudou o movimento:

Dispensamo-nos de dar ênfase à certeza de que, nesta Casa, somos todos (...) cruzados valorosos do respeito à ordem jurídica $\mathrm{e}$ à Constituição. (...) E ainda agora, antecipando-nos à derrocada das forças subversivas, acionadas por dispositivos governamentais, que visavam, já sem disfarces, à destruição do primado da democracia e à implantação de um regime totalitário (...), tivemos a lucidez e o patriotismo de alertar, na memorável reunião extraordinária de 20 de março p. findo, os poderes constituídos da República para a defesa da ordem jurídica e da Constituição, tão seriamente ameaçadas. Mercê de Deus, sem sairmos da órbita constitucional, podemos hoje, erradicado o mal das conjuras comuno-sindicalistas, proclamar que a sobrevivência da Nação Brasileira se processou sob a égide intocável do Estado de Direito (CF-OAB, Ata de sessão do CF, 7/4/1964).

Note-se que o argumento utilizado pelo bâtonnier para justificar a deposição de Goulart era exatamente o mesmo usado pelos artífices do golpe de Estado: o de que ele teria sido executado para, evitando a subversão comunista encampada pelo governo federal, conservar a ordem jurídica. Contudo, o Conselho Federal mostrou-se transigente na defesa da legalidade. Não apenas porque fechou os olhos à ruptura constitucional representada pela destituição de Goulart, mas também porque, ao ceder seu presidente à Comissão Geral de Investigações (CGI), referendou a perseguição inquisitorial contra os inimigos do novo regime conduzida pelos responsáveis pelos Inquéritos Policiais-Militares (IPMs).

Nesse período, o único obstáculo ao apoio da OAB à ditadura militar foram as violações às prerrogativas dos advogados cometidas por autoridades encarregadas da repressão política. Na sessão de 15 de outubro de 1964, um notório arauto do novo regime no interior do Conselho Federal, Wilson Regalado da Costa, levou ao conhecimento de seus pares um incidente ocorrido entre o presidente da seção da $\mathrm{OAB}$ de Goiás, Rômulo Gonçalvez, e o comandante do $10^{\circ} \mathrm{Ba}$ talhão de Caçadores, o tenente-coronel Danilo de Sá da Cunha e Melo. O Conselho Federal solidarizou-se com Rômulo Gonçalvez, afrontado pelo oficial ao tentar interceder pelo cumprimento de um habeas corpus em favor de um preso polí- 
tico (CF-OAB, A ta de sessão do CF, 15/10/1964). Deste modo, percebe-se que, já nos meses iniciais do novo regime, nasceu uma fonte de atrito entre o governo e a $\mathrm{OAB}$ que contribuiu de maneira importante para que a entidade, na década de 1970, se deslocasse para a oposição à ditadura militar: as arbitrariedades de autoridades policiais e militares contra advogados e o desrespeito dessas mesmas autoridades às prerrogativas profissionais dos advogados.

De todo modo, o Conselho Federal recebeu satisfeito os convites feitos, logo nos primeiros meses do novo regime, para colaborar com o governo. $\mathrm{O}$ organismo percebia o novo padrão de relacionamento com o Executivo como uma recuperação de seu prestígio. $\mathrm{A}$ OAB voltava a ser tratada com deferência pelo governo. Assim, ainda em abril de 1964, Povina Cavalcanti foi recebido pelo ministro do Trabalho para tratar de uma questão cara à entidade: a previdência dos advogados. A deposição de Goulart renovou as esperanças do Conselho Federal da OAB de implementar seu plano previdenciário. Depois de se reunir com o ministro, Povina Cavalcanti relatou que ele manifestara "boa vontade (...) na solução do caso". O bâtonnier emendou acreditar que, dali a dois meses, "teríamos uma solução definitiva para o problema" (CF-OAB, Ata de sessão do CF, 28/4/1964).

Ao mesmo tempo, o Conselho Federal era convocado para integrar comissões governamentais. No dia 28 de abril, o presidente da OAB informou ao Conselho Federal ter sido designado por Castelo Branco membro da comissão incumbida de verificar o estado de saúde dos integrantes da comissão comercial chinesa presos pelo Exército. No seu relato, o presidente da Ordem interpretou sua nomeação como uma "consideração especial" de Castelo Branco (CF-OAB, Ata de sessão do CF, 28/4/1964). Semanas depois, Povina Cavalcanti foi designado vice-presidente da Comissão Geral de Investigações. Novamente, o Conselho Federal reconheceu a nomeação como uma deferência governamental à $\mathrm{OAB}$ (CF-OAB, Ata de sessão do CF, 26/5/1964).

\section{A participação dos conselheiros federais na ditadura militar}

Vitorioso o golpe, os integrantes do Conselho Federal foram convocados a desempenhar tarefas importantes no novo regime. Considerando inicialmente apenas os bacharéis pertencentes ao Conselho Federal durante o governo Goulart, localizemos os que foram designados pelo novo regime para exercer funções-chave. Prado Kelly e Temístocles Cavalcanti foram nomeados ministros do STF. Povina Cavalcanti, como mencionado, foi nomeado vice-presidente da Comissão Geral de Investigações. Miguel Seabra Fagundes e Temístocles Cavalcanti compuseram uma comissão nomeada em 1966 por Castelo Branco com a incumbência de elaborar um anteprojeto de Constituição. Nehemias Gueiros foi o 
autor do texto do Ato Institucional $\mathrm{n}^{\circ}$ 2. Merece destaque a atuação de Carlos Medeiros Silva, que se tornou um importante artífice do arranjo institucional da ditadura militar. Ele foi, com Francisco Campos, autor do texto do Ato Institucional $\mathrm{n}^{\circ} 1$ e o responsável pelo anteprojeto de Constituição encaminhado pelo governo ao Congresso Nacional no final de 1966. Medeiros ainda redigiu a Lei de Imprensa e a Lei de Segurança Nacional de 1967, além de ter sido ministro da Justiça (Rollemberg, 2008; Abreu, 2002).

Num levantamento sucinto, foi possível identificar 22 bacharéis integrantes do Conselho Federal da $\mathrm{OAB}$ durante o período democrático que exerceram cargos no Executivo Federal ou mandatos parlamentares pelo partido de sustentação da ditadura militar, a Aliança Renovadora Nacional (Arena), nos governos Castelo Branco e Costa e Silva (Mattos, 2011: 134-135). Dos seis ex-presidentes da OAB ainda vivos em 1964, ao menos cinco desempenharam funções públicas nos primeiros anos da ditadura militar: Haroldo Valadão, Seabra Fagundes, Nehemias Gueiros, Alcino Salazar e Prado Kelly. Esses dados sugerem uma ampla adesão ao novo regime da fração da elite dos advogados que compunha o Conselho Federal desde 1945.

\section{Considerações finais}

No início da década de 1960, o Conselho Federal da OAB atuou diretamente na arena política. Sua postura em defesa da ordem jurídica não era neutra em relação às lutas que dividiam o país. A manutenção estrita da ordem jurídica impedia a expansão da cidadania política e social. O organismo, desde meados de 1962, aderiu à campanha que, denunciando a infiltração comunista no Brasil, preparou a deposição de Goulart. O apoio inequívoco do Conselho Federal ao golpe de Estado traiu o legalismo do órgão e revelou que, na sua hierarquia de valores, a defesa do status quo sobrepunha-se à defesa da ordem jurídica.

Proponho que o oposicionismo da $\mathrm{OAB}$ a Goulart se fundava na convergência de quatro fatores. Em primeiro lugar, os vínculos estreitos que os conselheiros federais mantinham com as classes dominantes. Em segundo lugar, a filiação dos integrantes do Conselho Federal a organizações políticas que articularam a deposição de Goulart, particularmente a UDN, o PSD e o complexo IPES/IBAD. Em terceiro lugar, a identificação da entidade com uma cultura política que julgava ilegítimos o reformismo do governo e a ascensão do movimento popular. Finalmente, a degradação das relações da OAB com o governo federal, num contexto em que a entidade se encontrava ameaçada pela emergência de associações e sindicatos concorrentes e desafiada pelo processo de proletarização dos advogados. 
Notas

1. É preciso lembrar os trabalhos pioneiros sobre o tema, como o de René Dreifuss (1981) e o de Heloisa Starling (1986). Entre a produção mais recente, para citar apenas alguns exemplos, encontram-se os de Daniel Aarão Reis Filho (2005), Denise Rollemberg (2008), Janaína Cordeiro (2009) e Kenneth Serbin (2002).

2. Refiro-me aos trabalhos de Marly Motta, Denise Rollemberg, Luiz Werneck Vianna e André Dantas, citados ao final do artigo.

3. Não era por acaso que os componentes ideológicos do udenismo analisados por Maria Victoria Benevides (1981: 241-275) guardavam grande proximidade com os elementos do oposicionismo do Conselho Federal aqui descritos.

4. É interessante registrar que alguns dos membros do Conselho Federal da OAB no governo Goulart passaram pelos cursos da Escola Superior de Guerra (ESG), um dos mais influentes centros de doutrinação anticomunista no pós-1945. Foram eles: Osvaldo de Souza Valle (turma de 1954), João Nicolau Máder Gonçalvez (turma de

\section{Referências bibliográficas}

\author{
ABREU, Alzira Alves de et alii (coord.). \\ Dicionário histórico-biográfico brasileiro, \\ pós-1930. Rio de Janeiro: CPDOC/FGV, \\ 2002. (CD-rom).
}

ADORNO, Sérgio. Os aprendizes do poder. Rio de Janeiro: Paz e Terra, 1988.
1955), Temístocles Brandão Cavalcanti (turma de 1958) e Wilson Regalado Costa (turma de 1964). Cf. http://www.esg.br/ a-esg/diplomados-da-esg/ Acesso em 13/ $12 / 2011$.

5. Marly Motta (2006) faz uma interessante análise da tensão entre os compromissos corporativos da $\mathrm{OAB}$ e sua atuação política.

6. Essas transformações foram estudadas, num trabalho pioneiro, por Olavo Brasil de Lima Júnior, Lúcia Klein e Antônio Martins (1970). Nele os autores analisam as repercussões impostas à categoria e à profissão de advogado pelo desenvolvimento capitalista brasileiro, como a dificuldade de absorção dos advogados pelo mercado de trabalho em virtude da inadequação da formação recebida nas faculdades frente às necessidades do desenvolvimento econômico e as modificações nas atividades profissionais dos advogados (assalariamento, migração dos advogados de escritórios de advocacia para grandes empresas privadas, advocacia preventiva dedicada, essencialmente, a atividades de consultoria e assessoria extrajudicial).

BENEVIDES, Maria Victoria. $A$ UDN e o udenismo. Rio de Janeiro: Paze Terra, 1981.

CALICCHIO, Vera. Verbete FAGUNDES, Seabra. In: ABREU, Alzira Alves de et alii (coord.). Dicionário histórico-biográfico brasileiro, pós-1930. Rio de Janeiro: CPDOC/ FGV, 2002. (CD-rom). 
COELHO, Fernando. A OAB e o regime militar (1964-1986). Recife: OAB - Seção Pernambuco, 1996.

DANTAS, André Vianna. A democracia na berlinda e a consolidação da OAB: entre a denúncia e a vigília (1946-1968). In: MOTTA, Marly Silva da \& DANTAS, André Vianna. História da Ordem dos Advogados do Brasil. Rio de Janeiro: OAB, 2006, v. 5 .

DREIFUSS, René Armand. 1964: a conquista do Estado. Petrópolis: Vozes, 1981.

FAGUNDES, Laura. Instituto dos Advogados Brasileiros: 150 anos de história, 18431993. Rio de Janeiro: IAB/Destaque, 1995.

FAUSTO, Boris. A revolução de 1930: historiografia e história. São Paulo: Companhia das Letras, 1997.

FICO, Carlos. Versões e controvérsias sobre 1964 e a ditadura militar. Revista Brasileira de História, São Paulo, vol. 24, n. 47, 2004.

GUEIROS, Nehemias. $A$ advocacia e o seu estatuto. Rio de Janeiro: Livraria Freitas Bastos, 1964.

HIPPOLITO, Lucia. De raposas e reformistas: o PSD e a experiência democrática brasileira, 1945-64. Rio de Janeiro: Paz e Terra, 1985.

LIMA JR., Olavo Brasil de; KLEIN, Lúcia Maria Gomes; MARTINS, Antônio Soares. O advogado e o Estado no Brasil. Rio de Janeiro: Edições Dados, 1970.

MALIN, Mauro. Verbete AUGUSTO, José. In: ABREU, Alzira Alves de et alii (coord.). Dicionário histórico-biográfico brasileiro, pós-1930. Rio de Janeiro: CPDOC/ FGV, 2002. (CD-rom).

MATTOS, Marco Aurélio Vannucchi Leme de. Os cruzados da ordem jurídica. A atuação da Ordem dos Advogados do Brasil Resumo
(OAB), 1945-1964. São Paulo, 2011. Tese (Doutorado em História). USP.

MOTTA, Marly Silva da. A Ordem dos Advogados do Brasil: entre a corporação e a instituição. Ciência Hoje, Rio de Janeiro, vol. 39, p. 32-37, 2006.

MOTTA, Rodrigo Patto Sá. Em guarda contra o perigo vermelho. São Paulo: Perspectiva/FAPESP, 2002.

OLIVEIRA, João Gualberto de. História dos órgãos de classe dos advogados. São Paulo: [s.n.], 1968.

REIS FILHO, Daniel Aarão. O colapso do colapso do populismo. In: FERREIRA, Jorge (org.). O populismo e sua história. Rio de Janeiro: Civilização Brasileira, 2001.

ROLLEMBERG, Denise. Memória, opinião e cultura política. A Ordem dos Advogados do Brasil sob a ditadura (1964-1974). In: REIS, Daniel Aarão \& ROLLAND, Denis (orgs.). Modernidades alternativas. Rio de Janeiro: Editora FGV, 2008.

SAES, Décio. Classe média e política no Brasil, 1930-1964. In: FAUSTO, Boris (dir.). História geral da civilização brasileira. Rio de Janeiro: Bertrand Brasil, 1996, tomo 3 , volume 3 .

SCHUBSKY, Cássio. Advocacia: a trajetória da Associação dos Advogados de São Paulo. São Paulo: Lettera.doc, 2006.

SKIDMORE, Thomas. Brasil: de Getúlio a Castelo. Rio de Janeiro: Paz e Terra, 1982.

TOLEDO, Caio Navarro de. O governo Goulart e o golpe de 64. São Paulo: Brasiliense, 2004.

VIANNA, Luiz Werneck. Os intelectuais da tradição e a modernidade: os juristas-políticos da OAB. In: Travessia: da abertura à Constituinte. Rio de Janeiro: Livraria Taurus Editora, 1986. 
O presente artigo examina o combate travado pela $\mathrm{OAB}$, por meio de sua instância diretiva máxima, o Conselho Federal, contra o governo Goulart. A atuação oposicionista da $\mathrm{OAB}$ deve ser compreendida no quadro da mobilização civil que colocou em marcha uma campanha de desestabilização do governo federal. Deposto Goulart, a OAB, como instituição, e os conselheiros federais, individualmente, colaboraram ativamente com a ditadura militar nos seus primeiros anos. Propõe-se que o oposicionismo da $\mathrm{OAB}$ ao governo Goulart derivasse de quatro fatores: os interesses socioeconômicos dos conselheiros federais; seus vínculos político-partidários; a cultura política dominante no Conselho Federal; questões corporativo-institucionais.

Palavras-chave: OAB; governo Goulart; golpe de 1964; advogados.

\section{Abstract}

This article examines OAB's struggle, through its highest directive instance, the Federal Council, against Goulart's Government. OAB oppositionist operation should be understood into the civil mobilization scenario which provoked a campaign of destabilization of the Federal Government. After Goulart's deposition, OAB, as an institution, and the federal counselors, individually, cooperated on an active basis with the military dictatorship over its early years. It is proposed that OAB's oppositionism against Goulart's Government arose out of four factors: federal counselors' social and economic interests; their politic and partisan bonds; the dominant politic culture in the Federal Council; corporate and institutional issues.

Key words: OAB; Goulart's Government; 1964 coup; attorneys.

\section{Résumé}

Cet article examine la lutte menée par l'OAB, par l'intermédiaire de son instance supérieure de direction, le Conseil Fédéral, contre le gouvernement Goulart. Laction oppositionniste de l'OAB doit être comprise dans le cadre de la mobilisation civile qui a mis en œuvre une campagne de déstabilisation du gouvernement fédéral. Une fois Goulart destitué, l'OAB, en tant qu'institution, et les conseillers fédéraux, individuellement, ont collaboré activement avec la dictature militaire au cours des premières années. La proposition, ici, est que l'opposition de l'OAB au gouvernement Goulart dérive de quatre facteurs: les intérêts socio-économiques des conseillers fédéraux; leurs liens politiques-partisans; la culture politique dominante au Conseil Fédéral; des questions corporatives et institutionnelles. Mots-clés: OAB; gouvernement Goulart; coup d'état de 1964; avocats. 